\title{
ANÁLISE DE FATORES ERGONÔMICOS DO AMBIENTE DE TRABALHO NAS ATIVIDADES DE PODA DE ÁRVORES NO DISTRITO FEDERAL
}

\author{
Nilton César Fiedler ${ }^{1}$ Fabrício Coelho ${ }^{2,}$ Luciano José Minetti ${ }^{3}$
}

\begin{abstract}
RESUMO
Esta pesquisa foi realizada durante as atividades de poda de árvores na arborização urbana no Distrito Federal, durante o período de agosto a dezembro de 2003. Teve como objetivo geral analisar os fatores ergonômicos do ambiente de trabalho, tais como condições climáticas, os níveis de ruído e a iluminação. As condições climáticas foram medidas com o IBUTG. O nível de ruído foi avaliado, utilizando-se um decibelímetro colocado ao nível do ouvido do trabalhador, conforme preceitua a NR 15. A iluminância foi medida com um luxímetro a $0,75 \mathrm{~m}$ do solo, conforme a NBR 5413/92. O IBUTG não estava de acordo com a Norma Regulamentadora $n^{\circ} 15$, no período das 12 às 15 horas, apresentando o valor máximo de $27^{\circ} \mathrm{C}$ às 13 horas. Os maiores níveis de ruído foram encontrados nas fases de corte e traçamento com média de 101,5 dB (A). A lluminância estava de acordo com a NBR 5413/92, que estabelece níveis mínimos entre 200 e 500 LUX. Os níveis variaram de 362 a 969 Lux.
\end{abstract}

Palavras-chave: avaliação ergonômica; fatores ambientais arborização urbana.

\section{ABSTRACT \\ Analysis of ergonomic factors in the work environment in tree pruning activities in Distrito Federal, Brazil}

This research was done during tree pruning activities in the urban zones of Distrito Federal, Brazil, during August-December 2003, to analyze the ergonomic factors of work environment, especially climatic conditions, illumination and noise level. The climatic conditions were measured with the help of an IBUTG digital thermometer. The noise level was measured with the use of a sound level meter placed at worker's ear level, according to NR 15. The luminance was evaluated by use of a luximeter placed $0,75 \mathrm{~m}$ above the ground, in accordance to the NBR 5413/92. The humid bulb index and globe thermometer (IBUTG) did not comply with the regulatory norm 15 , from noon to $3 p . m$., with maximum temperature of $27^{\circ} \mathrm{C}$ at $1 \mathrm{p} . \mathrm{m}$. The highest noise level, averaging $101,5 \mathrm{~dB}(\mathrm{~A})$, occurred during cutting operations. The light intensity varied between 362 and 969Lux, which is within the NBR 54131/92 that establishes minimum level of 200 to 500 Lux.

Keywords: ergonomic evaluation, environmental factors, Urban afforestation.

\footnotetext{
Recebido para publicação em 03.05.2005

${ }^{1}$ Prof. Associado, Depto. Eng. Florestal - Universidade Federal do Espírito Santo - fiedler@pq.cnpq.br

${ }^{2}$ Eng. Florestal - Universidade de Brasília - Cx. Postal 04357 - CEP 70910-900 Brasília - DF

${ }^{3}$ Professor adjunto do Depto de Engenharia Elétrica e de Produção - UFV - minetti@ ufv.br
} 


\section{INTRODUÇÃO}

A arborização das cidades surgiu como uma maneira de melhorar a qualidade de vida nos grandes centros urbanos. Uma arborização bem planejada resulta em vários benefícios. No entanto, um plantio mal feito ou em local errado, juntamente com a necessidade de adequação de espaços no meio urbano, resultará em necessidade de poda (Silva, 2003).

Durante a poda de árvores, normalmente, os trabalhadores escalam troncos, em cima de veículos ou escadas apropriadas. Usualmente utilizam motosserras, serras elétricas, podões, serrotes de poda, foices e facões. Vários fatores podem influenciar o rendimento dos trabalhadores. As condições ambientais constituem uma grande fonte de tensão, durante o trabalho. $\mathrm{Na}$ atividade de poda, os trabalhadores estão expostos a estas condições.

Quando as condições de trabalho são desfavoráveis, ocorre fadiga, extenuações físicas e nervosas, diminuição no rendimento, aumento dos erros e riscos de acidentes no trabalho, além de facilitar a exposição do organismo a diversas doenças. O trabalhador, instintivamente, procura melhorar seu conforto, o que pode afetar sua atenção durante a atividade específica que está realizando e favorecer, a distração e as conseqüentes perdas de eficiência e segurança no trabalho (Couto, 1995).

Avaliando as associações entre ruídos e vibrações no posto de trabalho de motoristas de ônibus urbanos, Silva e Mendes (2005) concluíram que os veículos, que ofereciam riscos à saúde do trabalhador quanto a estes aspectos, era apenas os ônibus com motor dianteiro. Neste aspecto, a avaliação ergonômica contribuiu, parta tomada de decisão da empresa proprietária, quanto, à aquisição apenas dos modelos com motor traseiro.

O ser humano possui grande capacidade para ajustar-se às condições que the são impostas, adaptando-se rapidamente às situações. Assim, ele tem a capacidade de manusear máquinas, ferramentas e equipamentos ergonomicamente mal projetados, suportando posições incômodas e inadequadas durante o trabalho (Fiedler, 1998).

A ergonomia pode contribuir para solucionar um grande número de problemas sociais relacionados à saúde, segurança, conforto, eficiência e para prevenção de erros, melhorando o desempenho (Dul \& Weerdmeester, 1995).

Esta pesquisa teve como objetivo geral analisar os fatores ergonômicos do ambiente de trabalho, a que estão expostos os trabalhadores durante as atividades de poda de árvores no Distrito Federal. Especificamente, objetivou-se analisar as condições climáticas do ambiente de trabalho, avaliar os níveis de ruído a que estavam expostos os trabalhadores, avaliar os níveis de iluminação e fornecer subsídios para execução do trabalho com maior saúde, conforto, segurança, satisfação e bem-estar.

\section{MATERIAL E MÉTODOS}

Esta pesquisa foi realizada durante as atividades de poda na arborização urbana, no Distrito Federal, durante o período de agosto a dezembro de 2003. No Distrito Federal, para o corte e a poda de árvores, adota-se uma política de intervenção mínima, baseada no Decreto n. 014.783 de 17 de junho de 1993 que dispõe sobre o tombamento de espécies arbóreas arbustivas.

A jornada de trabalho dos operadores de poda tinha a duração de 8 horas, iniciando às $8 \mathrm{~h}$ e terminando às $17 \mathrm{~h}$, sendo um intervalo de 1 hora para o almoço, entre 12 e $13 \mathrm{~h}$.

A temperatura média anual da região varia entre 18 e $20{ }^{\circ} \mathrm{C}$. O período de setembro a outubro é o mais quente, com temperatura média entre 20 e $22{ }^{\circ} \mathrm{C}$. A umidade relativa do ar varia de $70 \%$ a $85 \%$ no verão e parte da primavera, decrescendo para 40 a $65 \%$ durante 0 inverno (Silva Júnior, 2004). 
O tamanho da amostra de trabalhadores e o número mínimo de repetições foram estabelecidos a partir de uma amostragempiloto, analisada por meio da seguinte fórmula, proposta por Conaw (1977):

$$
n \geq \frac{t^{2} * s^{2}}{e^{2}}
$$

em que,

$\mathrm{n}$ = número de pessoas ou de repetições necessárias;

$\mathrm{t}=$ coeficiente tabelado a $5 \%$ de probabilidade;

$\mathrm{s}=$ desvio-padrão da amostra; e

$e=$ erro admissível $=5 \%$.

A exposição ao calor foi medida com o uso de um termômetro digital de IBUTG modelo TGD- 200, montado nas frentes de trabalho. Os dados foram coletados a partir das 8 horas, em intervalos de 1 hora, até às 17 horas, conforme metodologia utilizada por Silva (1999), durante os meses de agosto a dezembro. Os valores foram comparados àqueles da Legislação Brasileira de atividades e operações insalubres por meio da NR 15 ANEXO 3 (SEGURANÇA E MEDICINA DO TRABALHO, 2004).

Efetuou-se uma análise de variância, considerando um delineamento inteiramente ao acaso, com 10 tratamentos (períodos do dia, em horas) e 12 repetições, utilizando-se o teste de Tukey.

Os fatores ergonômicos foram avaliados por meio de um decibelímetro da marca Lutron modelo SL-4001, colocado ao nível do ouvido do operador, conforme preceitua a NR 15 (SEGURANÇA E MEDICINA DO TRABALHO, 2004). Os dados foram coletados a intervalos de 1 minuto, durante as fases de corte, traçamento, deslocamento, pausa e manutenção. Os resultados foram comparados com os valores máximos, permitidos pela Legislação Brasileira NR 15 ANEXO 1. As motosserras utilizadas pelos operadores eram da marca
STIHL, modelo 034 e motopoda era da marca Power Proner modelo 2100.

Foram efetuadas duas análises de variância, uma para as fases de corte e traçamento, com 2 tratamentos e 49 repetições, outra para a fase de deslocamento, com 3 tratamentos e 30 repetições. Usou-se o teste de Tukey, para comparação das médias dos diversos tratamentos.

Os tempos foram cronometrados, durante toda a jornada de trabalho. Foi utilizado o método contínuo, ou seja, com medição do tempo sem detenção do cronômetro e classificado da seguinte forma:

1. Fase 1 (Corte) - derrubada de árvores e corte de galhos;

2. Fase 2 (Traçamento) - corte das toras em toretes;

3. Fase 3 (Deslocamento) - deslocamento do operador durante a execução do trabalho;

4. Fase 4 (Pausa) - tempo em que o trabalhador está parado em descanso; e

5. Fase 5 (Manutenção) - tempo gasto com manutenção das máquinas.

No local de trabalho a iluminância foi medida com um luxímetro de marca Lutron modelo $\mathrm{LX}-101$ a $0,75 \mathrm{~m}$ do solo. Os dados foram coletados, a partir das 8 horas, com intervalo de 1 hora até às 17 horas. A metodologia de medição, bem como a análise comparativa dos resultados, foi feita de acordo com a NR-17 (SEGURANÇA E MEDICINA DO TRABALHO, 2004; e NBR 5413/92).

\section{RESULTADOS E DISCUSSÃO}

A exposição ao calor foi avaliada, durante a jornada de trabalho, através do Índice de Bulbo Úmido e Termômetro de Globo (IBUTG), sendo os resultados apresentados na Figura 1. 


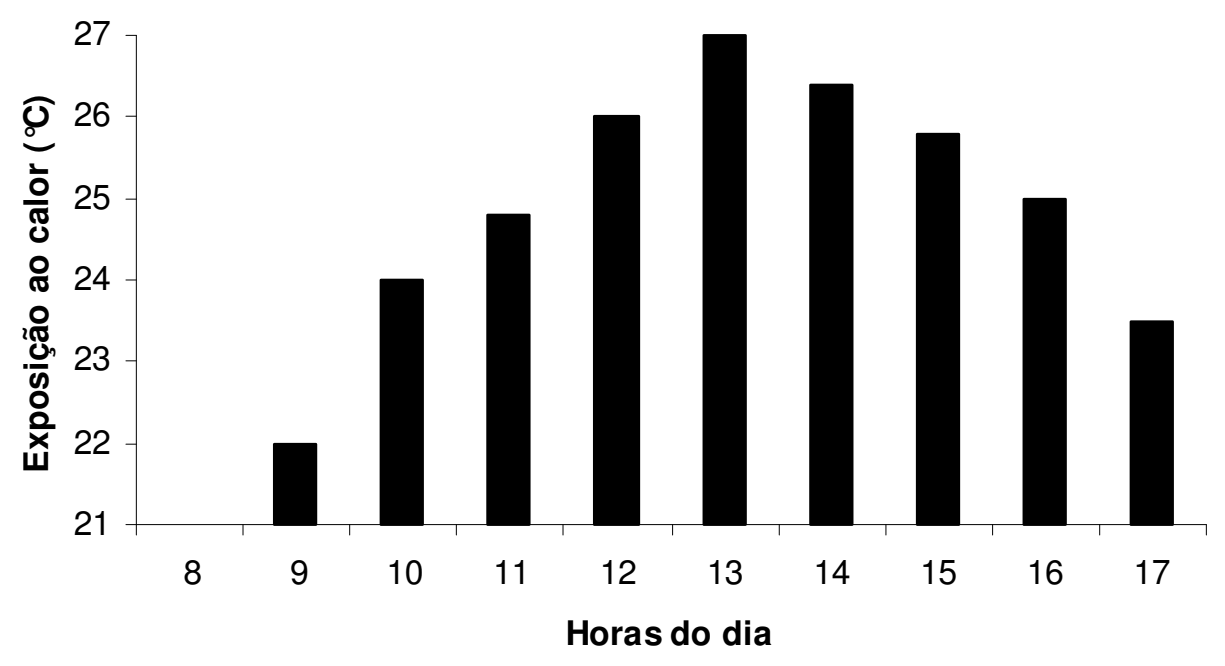

Figura 1. Valores de IBUTG médios durante a jornada de trabalho.

Verificou-se que o comportamento do IBUTG médio, durante a jornada de trabalho, foi crescente até às 13 horas, quando atingiu o seu máximo $\left(27^{\circ} \mathrm{C}\right)$ e em seguida apresentou declínio menos acentuado até às 17 horas.

A NR $n^{\circ} 15$ preceitua que quaisquer trabalhos pesados ou leves, contínuos ou não, podem ser realizados até um limite de IBUTG de $25^{\circ} \mathrm{C}$. O trabalho de poda é considerado pesado devido suas características. Portanto, de acordo com as condições térmicas apresentadas entre 12 e 15 horas, para cada hora corrida de trabalho, o operador pode trabalhar 45 minutos no máximo e descansar no mínimo 15 minutos.

A umidade relativa média para esse período foi de $40 \%$, valor este considerado limite para a zona de conforto térmico, segundo lida (1990).

Foram feitas 12 observações por período, quando o mínimo necessário totalizava quatro observações. De acordo com os resultados da análise de variância para o IBUTG, durante os períodos diurnos, foram verificadas diferenças significativas, ao nível de $1 \%$ de probabilidade, entre os períodos considerados.

Esses resultados expressaram apenas, as condições climáticas na época de coleta de dados. Para analisar mudanças que podem ocorrer durante as estações do ano, é necessária a realização de medições constantes durante todo o ano.

Para proteger o trabalhador exposto a condições térmicas desfavoráveis, é recomendada a utilização de roupas permeáveis, como as de algodão, para facilitar a troca de vapor d'água, regime de trabalho/pausas, segundo os valores de IBUTG encontrados e a programação das atividades deve ser feita para horas menos quentes e de menor incidência de insolação.

O ruído médio verificado variou de acordo com as fases do trabalho, fase 1 (corte), fase 2 (traçamento), fase 3 (deslocamento), fase 4 (pausa) e fase 5 (manutenção), conforme apresentado na Quadro 1.

Os resultados das análises de variância para os níveis de ruído, durante as etapas de trabalho, mostraram que existem diferenças significativas, ao nível de $1 \%$ de probabilidade. O teste de Tukey mostrou que existe diferença significativa entre as fases de corte e traçamento e as fases de deslocamento, pausas e manutenção. Pode-se dividir estas em dois grupos distintos: grupo 1 - corte e traçamento; e grupo 2 deslocamento,pausa e manutenção. Há diferença significativa apenas entre os grupos. 
Quadro 1. Níveis médios de ruído para cada etapa de trabalho

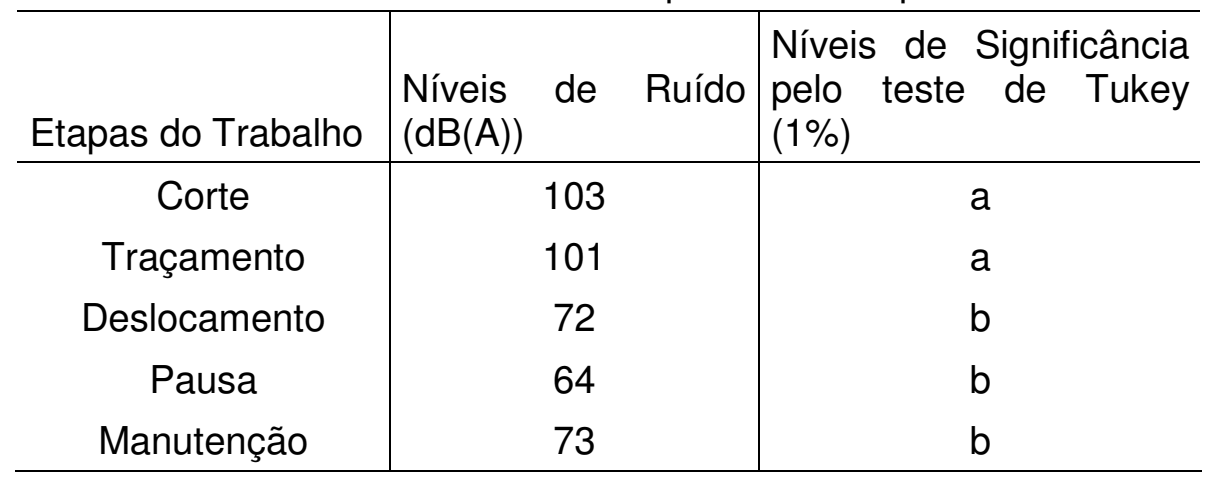

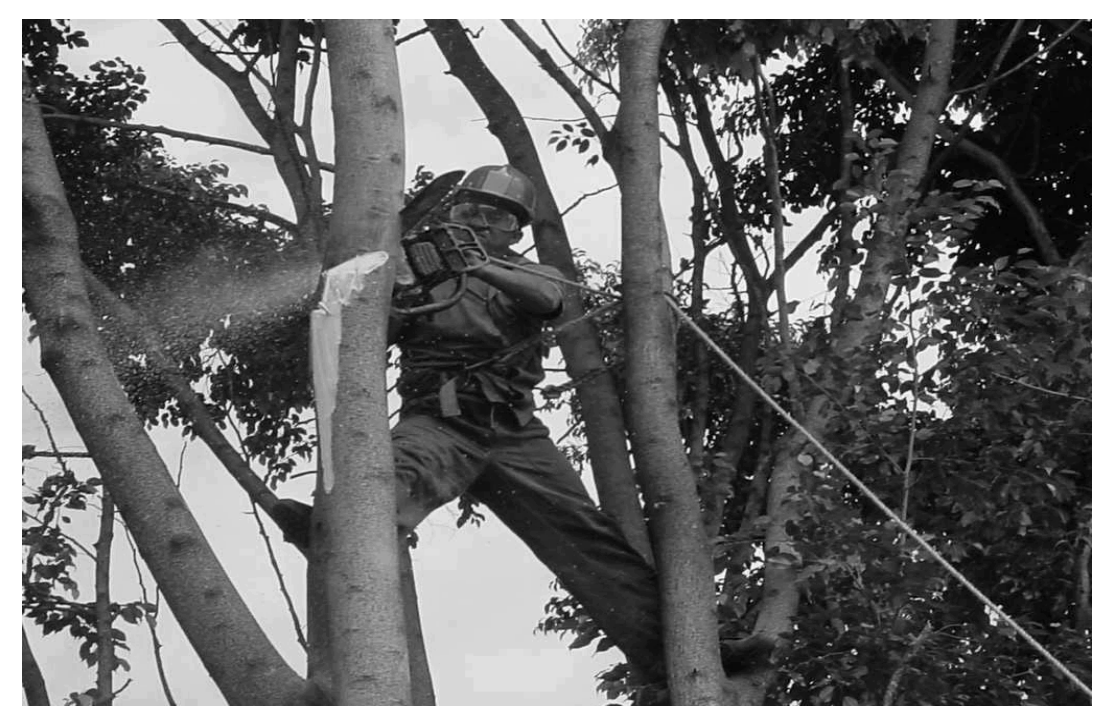

Figura 2. Atividade de corte.

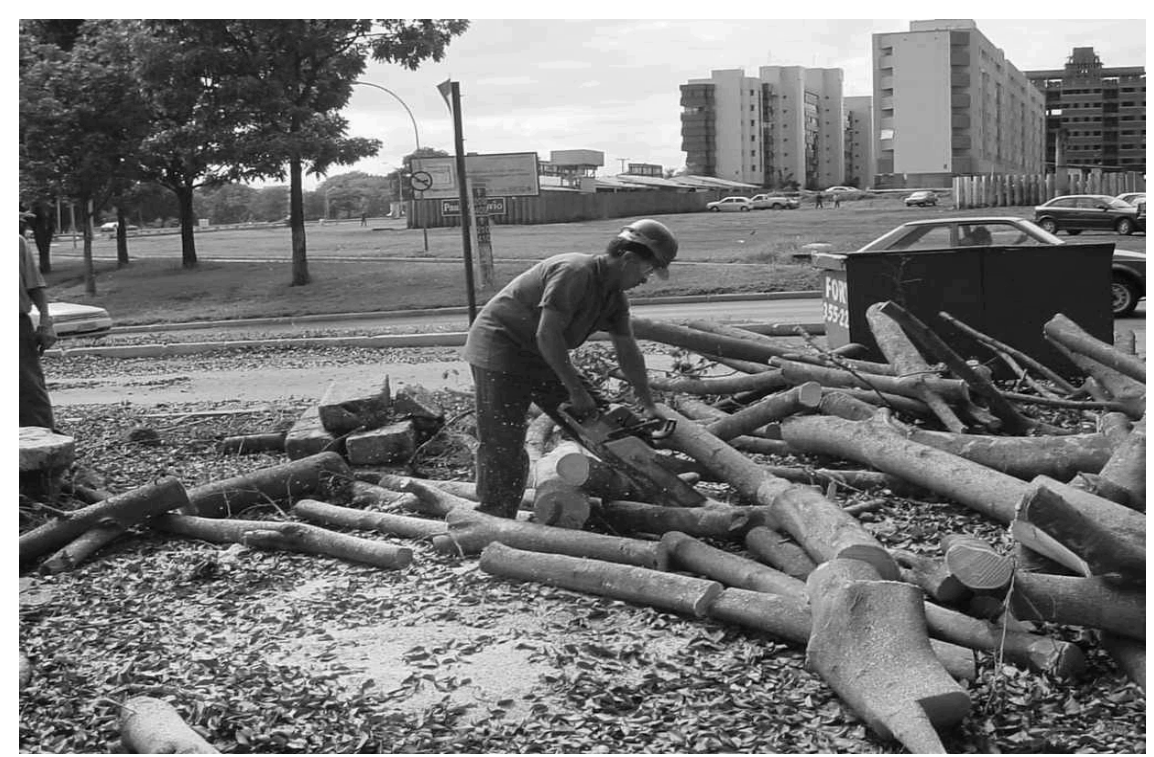

Figura 3. Atividade de traçamento - corte das toras em toretes. 
As figuras 3 e 4 mostram as atividades de corte e traçamento, que apresentaram os maiores níveis de ruído entre as fases pesquisadas.

Com base no estudo de tempos e movimentos, verificou-se que os operadores passaram em média $84 \%$ do tempo nas fases 1 e 2, mas $16 \%$ nas outras fases. Os maiores níveis de ruído foram observados nas duas primeiras fases, atingindo a $101,5 \mathrm{~dB}(\mathrm{~A})$ em média.

Para uma jornada de trabalho de 8 horas diárias, a exposição máxima permitida sem proteção auricular é de $85 \mathrm{~dB}(\mathrm{~A})$, conforme a Norma Regulamentadora $n^{\circ} 15$, em seu anexo 1. De acordo com esta norma, os trabalhadores não podem ficar expostos aos níveis de ruído, durante o corte e o traçamento da madeira, sem uma proteção adequada. Para cada aumento de $5 \mathrm{~dB}$ no nível de ruído, o tempo de exposição deve ser reduzido pela metade. Nestas fases, o tempo máximo de exposição sem o uso de proteção é de 45 minutos. As outras fases do trabalho podem ser executadas, durante toda a jornada de trabalho, sem o uso de proteção auricular.

Avaliando os níveis de ruído de diversas motosserras durante o corte de madeira no interior de São Paulo, Minetti (1996) concluiu que os níveis médios mais altos ocorreram na atividade de toragem (102,1 dB(A)) e no corte $(101,2 \mathrm{~dB}(\mathrm{~A}))$.

Foram feitas 52 observações em média, enquanto o mínimo necessário era de 32 observações.
Para eliminar problemas acarretados pelo ruído, a melhor alternativa é a diminuição dos níveis na fonte, ou seja, adquirir máquinas menos ruidosas ou proceder a constante manutenção das máquinas. Quando essas medidas não eliminarem completamente o problema, deve-se realizar uma reorganização do trabalho de modo que o máximo de tempo permitido, em cada fase do ciclo, não exceda os níveis permitidos, ou ainda a alternância de funções. Como última medida, deve-se proteger 0 trabalhador com protetor auricular. É importante a realização periódica de testes audiométricos nos trabalhadores, afim de detectar problemas advindos do trabalho. Os níveis de iluminância determinados são apresentados na Figura 4.

De acordo com a NBR 5413/92, a iluminância mínima necessária para trabalho bruto de maquinaria deve estar entre 200 e 500 Lux, sem, no entanto estabelecer um nível máximo. Assim, a iluminância medida para a atividade de poda está de acordo com os níveis estabelecidos pela Norma. Como os valores médios em nenhum momento ultrapassaram o valor de 1000 Lux, não há necessidade de proteção especial para a visão. A proteção deve ser utilizada principalmente para evitar o contato de serragem, galhos e outras substâncias provenientes da poda. $\mathrm{Na}$ atividade de poda, os trabalhadores passam grande parte do tempo olhando para cima. Desse modo, ficam expostos diretamente aos raios solares, o que pode provocar desconforto da visão, podendo levar, conseqüentemente, a acidentes de trabalho.

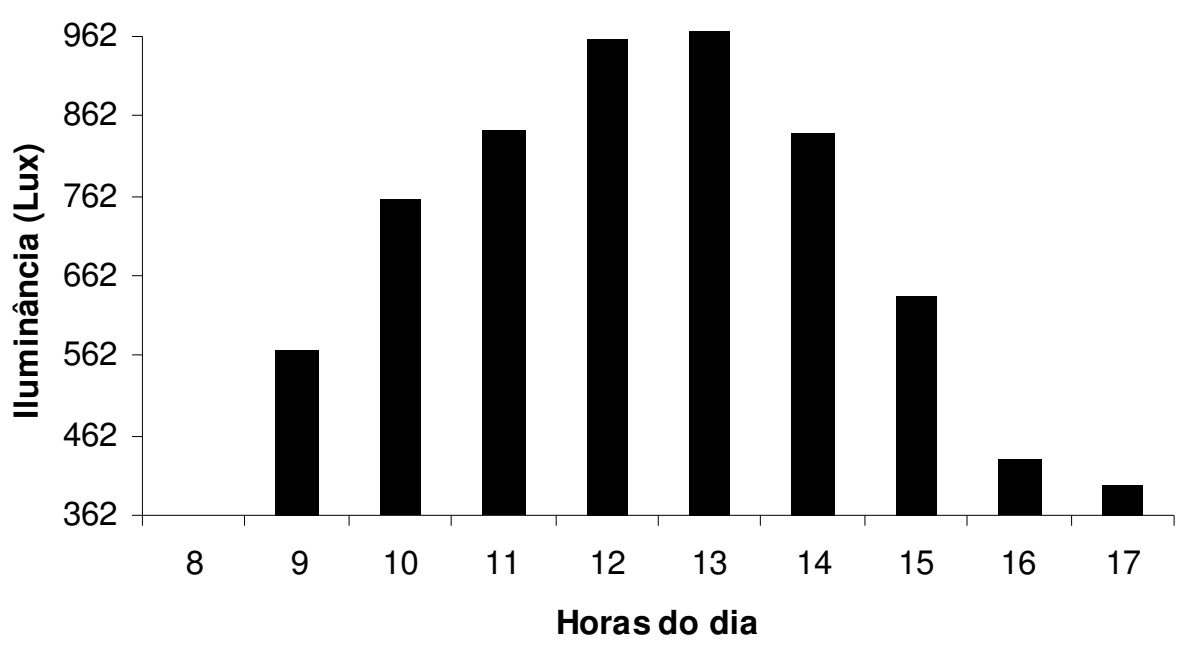

Figura 4. Níveis médios de iluminância, em função do horário. 
De acordo com a análise de variância houve diferença significativa entre os períodos do dia com relação à iluminância. Foram feitas 36 observações por período, enquanto o mínimo necessário era de 25 observações.

A partir de 1000 LUX, o aumento da iluminância não provoca melhoras sensíveis no rendimento, e a fadiga visual começa a aumentar. Dessa forma, recomenda-se usar 2000 Lux, praticamente, como máximo (lida, 1990). Em níveis de iluminância acima de 1000 Lux, o trabalhador deve ser protegido com óculos ou o trabalho pode ser reorganizado, de forma a diminuir o tempo de exposição direta ao excesso de luminosidade, com alternância de funções ou de locais mais ou menos expostos.

\section{CONCLUSÕES E RECOMENDAÇÕES}

- Os trabalhadores são expostos a condições climáticas inadequadas, no período das 12 às 15 horas, especialmente às 13 horas;

- Para o IBUTG, foram verificadas diferenças significativas, ao nível de $1 \%$ de probabilidade, entre os períodos considerados, variando em função do horário do dia;

- Durante as etapas de corte e traçamento, é necessário utilizar protetores auriculares ou diminuir o tempo de exposição do trabalhador;

- Os níveis de iluminância estimados foram adequados, segundo a NBR 5413/92 e não devem causar fadiga visual nos trabalhadores;

- Os níveis de iluminância variaram, em função do horário.

\section{REFERËNCIAS BIBLIOGRÁFICAS}

CONAW, P.L. Estatística. São Paulo: Edgard Blucher, 1977. 264 p.
COUTO, H.A. Ergonomia aplicada ao trabalho - o manual técnico da máquina humana. Belo Horizonte: Ergo Editora, 1995, v. $1.353 \mathrm{p}$.

DUL, J., WEERDMEESTER, B. Ergonomia Prática. Trad. de Itiro lida. Editora Edgard Blucher. São Paulo. 1995.147p.

FIEDLER, N.C. Análise de posturas e esforços despendidos em operações de colheita florestal no Litoral Norte do Estado da Bahia. Viçosa, MG, 103 p. Tese (Doutorado em Ciência Florestal) Universidade Federal de Viçosa, 1998.

IIDA, I. Ergonomia: projeto e produção. São Paulo: Edgard Blucher, $1990 . \quad$ 465p.

MINETTE, L.J. Análise de fatores operacionais e ergonômicos na operação de corte florestal com motosserra. Viçosa, UFV, 1996. 211p. (Tese D.S).

NBR 5413/92. Disponível em www.inmetro.gov.br. Acesso em 20/07/03.

SEGURANÇA E MEDICINA DO TRABALHO. 54, ed. São Paulo: Atlas (Manuais de Legislação Atlas). 2004. 771 p.

SILVA.M.A. Poda em árvores. Manual de jardinagem e produção de mudas do Departamento de parques e jardins-DPJ. NOVACAP. Brasília, 2003. 136p.

SILVA, K.R. Análise de fatores ergonômicos em marcenarias do município de Viçosa - MG. Viçosa, MG: UFV, 1999. 97 p. Dissertação (Mestrado em Ciência Florestal) - Universidade Federal de Viçosa, 1999. 